Portland State University

PDXScholar

2013

\title{
Tutor-Facilitated Adult Digital Literacy Learning: Insights from a Case Study
}

\author{
Kimberly D. Pendell \\ Portland State University, kpendell@pdx.edu \\ Elizabeth Withers \\ Portland State University \\ Jill Castek \\ Portland State University \\ Stephen Reder \\ Portland State University
}

Follow this and additional works at: https://pdxscholar.library.pdx.edu/ulib_fac

Part of the Library and Information Science Commons

Let us know how access to this document benefits you.

\section{Citation Details}

Pendell, Kimberly D.; Withers, Elizabeth; Castek, Jill; and Reder, Stephen, "Tutor-Facilitated Adult Digital Literacy Learning: Insights from a Case Study" (2013). Library Faculty Publications and Presentations. Paper 159. http://archives.pdx.edu/ds/psu/13005

This Post-Print is brought to you for free and open access. It has been accepted for inclusion in Library Faculty Publications and Presentations by an authorized administrator of PDXScholar. Please contact us if we can make this document more accessible: pdxscholar@pdx.edu. 
Tutor-facilitated adult digital literacy learning: Insights from a case study

Kimberly D. Pendell Social Work and Social Sciences Librarian, Assistant Professor, Portland State University Library kpendell@pdx.edu

Elizabeth Withers, Master of Science in Sociology, Doctoral Student, Portland State University elizabew@pdx.edu

Dr. Jill Castek, Research Assistant Professor, Department of Applied Linguistics, Portland State University jcastek@pdx.edu

Dr. Stephen Reder, Professor, Department of Applied Linguistics, Portland State University reders@pdx.edu

Published in: Internet Reference Services Quarterly, 18:105-125, 2013

http://www.tandfonline.com/doi/pdf/10.1080/10875301.2013.800013

Abstract: While the digital divide has decreased, those who are still unable to access and use information and communication technologies are left further behind. An effective digital literacy program helps underserved populations gain needed skills and alleviate the demand placed on public library staff. This case study presents findings on a digital literacy learning model that utilizes a self-paced online platform and in-person volunteer tutors. The researchers found that the learner/tutor relationship is an essential part of the learning process, and that tutors develop a variety of strategies for helping learners. The researchers also identify aspects of effective program implementation.

Acknowledgements: This research was supported by a National Leadership Grant from the Institute of Museum and Library Services to Portland State University (LG-06-11-0340-11). The authors also wish to acknowledge the many contributions of Jenny Lind Withycombe and Andrew Pizzolato to the research project. 


\section{TUTOR-FACILITATED ADULT DIGITAL LITERACY LEARNING}

\section{Tutor-facilitated Adult Digital Literacy Learning: Insights from a Case Study}

\section{Introduction}

The ubiquity of computers and the Internet in the work and home life of most Americans can easily mask the one third of the U.S. population who does not regularly use information and communication technologies (ICT) (National Telecommunication and Information Administration [NTIA], 2011, p. 5). As government services, job-seeking, and even a sizable portion of social interactions are increasingly available only online, this population is at greater risk of being left further behind due to their limited access and ability to use these important resources. Since the "digital divide" was identified, numerous policies and programs have sought to eliminate it, and while the size of the "have nots" has decreased over the years, the importance of digital inclusion has grown. Access to computers and the Internet alone is not enough to enable effective ICT use among current non-users - digital literacy is a necessary component of any program or policy promoting digital inclusion. Most recently, digital literacy was defined by the Digital Literacy Task Force of the American Library Association (2013) as "the ability to use information and communication technologies to find, understand, evaluate, create, and communicate digital information, an ability that requires both cognitive and technical skills" (p. 2).

Unsurprisingly, public computing and assistance with using computers and the Internet have become part of standard library services. Public librarians regularly assist low-skilled underserved adults with digital literacy related tasks, both in one-on-one interactions and in the computer skills classes offered in libraries nationwide. However, meeting the demand for these services can be challenging, particularly in a time of reduced staffing and resources. Developing 


\section{TUTOR-FACILITATED ADULT DIGITAL LITERACY LEARNING}

digital literacy programs for local communities takes time, staff, and expertise. An established learning platform and effective learning model could provide needed support for underserved populations seeking digital literacy skills while also alleviating some of the demands placed on libraries and their staff.

This case study is part of a larger multi-state, multi-phase research study on the effectiveness of a self-paced and tutor-facilitated digital literacy learning model for underserved and vulnerable populations, funded by an Institute of Museum and Library Services (IMLS) National Leadership Grant. This learning model, which utilizes a web-based learning platform called the Learner Web, is currently used in a subset of the many Broadband Technologies Opportunities Program (BTOP) sites in the United States. This case study examines program implementation in one of the six BTOP/Learner Web regions and provides preliminary findings on tutors, learners, and the digital literacy learning process as observed at three computer labs using the self-paced model. The researchers' analyses of interviews and lab observation field notes from this one region suggest that the learner/tutor relationship is an essential part of the digital literacy learning process and that tutors develop a variety of strategies for helping learners. The researchers also identify effective strategies of program implementation and sustaining volunteer tutor engagement. Learners appeared to benefit from the self-paced learning process which allowed them to connect learning with their individual goals.

\section{Literature Review}

The following sections briefly describes the three primary components of this case study: a description of the underserved populations that do not have sufficient access or skills to engage in our current ICT-heavy landscape, the role of public libraries in providing public computing and assistance, and the adult digital literacy learning process. 


\section{TUTOR-FACILITATED ADULT DIGITAL LITERACY LEARNING}

\section{Identifying and Serving Vulnerable Populations}

The digital divide has been recognized since the mid-1990s when NTIA released the first report of the Falling through the Net series. This report identified the "haves" and "have nots" of computers and Internet access. The "have nots" were the urban and rural poor, urban and rural minorities, the young and old, and the less-educated (NTIA, 1995). Early policy attempted to provide access to computers and the Internet to these populations through programs like the School and Libraries program, known as E-rate, which subsidizes computer purchasing and Internet access for schools and libraries.

Since the early 2000s, NTIA's framework has changed from the digital divide to digital inclusion. Digital inclusion is a broader term that recognizes the underlying social conditions that determine ICT access and engagement. However, Epstein, Neisbit, and Gillespie (2011) suggested that the shift was more politicized, especially considering the shift in federal programs: "the extent that the discussion shifted from Internet access to high-speed broadband access, the government imperative was lessened and the discourse continued to evolve" (p. 102). Despite the overall increase nationally of home computer and Internet users over the years, along with diminishing disparities between the "haves" and "have nots," the demographics of the underserved populations have remained fairly consistent; those least likely to have adopted home broadband Internet include:

- lower income;

- minority groups (Black, Hispanic, or American Indian/Alaska Native);

- older adults;

- $\quad$ adults with less education;

- $\quad$ and persons with disabilities (NTIA, 2011).

Access to broadband in rural areas also remains lower than in urban areas (NTIA, 2011, p. 2). Lack of access and affordability likely contributes to the $44 \%$ of people in households below the 


\section{TUTOR-FACILITATED ADULT DIGITAL LITERACY LEARNING}

federal poverty line who use library computers to access the Internet (Becker, Crandall, \& Fisher, 2010, p. 2).

However, access is not the only reason why a portion of the U.S. population does not use ICT; affordability and relevance are the most highly cited reasons (NTIA, 2011, p. 5). The lack of skills to use ICT is also an obstacle for many; in 2010, an FCC survey reported that of the $35 \%$ of U.S. adults who have not adopted broadband at home, $22 \%$ cite digital literacy as the primary barrier (Horrigan, 2010, p. 5). Hargittai (2002) described this gap as the "second-level digital divide," which would require an investment in training and support in addition to existing access-focused programs. Many other scholars have challenged the idea that computer and Internet access alone was the hurdle for underserved populations to overcome. Rather, the digital divide is another aspect or replication of existing inequalities between socioeconomic groups (Duff 2011; Eubanks 2011; Mossberger, Tolbert \& Stansbury, 2003; van Dijk, 2005). Virginia Eubanks (2011) cautions against the "magical thinking" of policies that propose ICT access will result in new prosperity for those struggling at the bottom of the socioeconomic scale. "Seeing high-tech equity only as broadly shared access to existing technological products ignores other social values, neglects decision-making processes, sees citizens only as consumers, and ignores the operation of institutions and social structure" (p. 26). Access alone cannot fix the digital divide if the targeted groups do not have the cognitive and technical skills to use these technologies, cannot afford them, do not find them relevant and useful, or are not empowered to use them. While the targeted underserved populations are commonly measured in terms of their access to ICT (most recently in terms of high-speed broadband), the size of the underserved populations would likely be much larger if full digital inclusion were to be the metric.

\section{The Role of Public Libraries}




\section{TUTOR-FACILITATED ADULT DIGITAL LITERACY LEARNING}

Public libraries are recognized as an important resource for computer and Internet access in communities across the United States. The 2010 report, Opportunity for All: How the American Public Benefits from Internet Access at U.S. Libraries found public computing in libraries is used by $32 \%$ of the U.S. population, irrespective of age, income, computer skills, or even access at home (p. 2). Eighty-four percent of respondents also indicated that computer and Internet access in libraries was important for their community as a whole (p. 50).

The economic downturn increased the need for computer assistance, taking it to new highs, while state and local library budgets have simultaneously declined due to reduced revenues (ALA, 2011). Seventy-six percent of public libraries nationwide helped patrons complete online job applications and close to $97 \%$ of public libraries assisted patrons in accessing online government resources (ALA, 2012, p. 7). Almost half of U. S. public libraries currently provide some sort of formal computer and Internet related skills classes, but the other half struggles with limited staff and expertise to provide these classes (ALA, 2012, p. 7). Insufficient staff and lack of staff expertise are the primary obstacles for public libraries in helping patrons with online job searches and applications (Taylor, Jaeger, McDermott, Kodama, \& Bertot, 2012, p. 207). Rural libraries have the additional struggle of inadequate network connectivity for their communities (ALA, 2011, p. 9).

Librarian assistance is a critical part of the high demand on public computing in today's libraries. Jaeger, Bertot, Thompson, Katz, and DeCoster (2012) propose that patrons with Internet access at home still rely on public computing at their local library because "...likely the presence of a helpful, skilled librarian who can assist those who lack the necessary informationliteracy skills required to fill out online forms or search for vital information" (p. 13). The benefit of librarian assistance for those with low information or digital literacy skills resonates with 


\section{TUTOR-FACILITATED ADULT DIGITAL LITERACY LEARNING}

findings in digital literacy learning studies that suggest the learner's access to support and a comfortable environment are integral to the learning process and sustaining motivation.

\section{Adult Digital Literacy Learning}

Adult education and online learning both have generated robust amounts of research literature; however, the amount of literature specifically pertaining to adults acquiring computer and digital literacy skills is much smaller. A few studies stand out as the most relevant to the self-paced and tutor-facilitated learning model. Jimoyiannis and Gravani (2010) examined digital literacy instruction with adult learners in the Second Chance Schools (SCS) program in Greece. Program educators varied their instructional approach between classroom instruction and lessons; project based learning; and individual instruction sessions. The study identified four barriers to adult digital literacy acquisition in the SCS program:

- $\quad$ personal factors (e.g. lack of confidence, fear of computers and information technologies);

- learning factors (e.g. existing learning habits);

- educators' pedagogical factors (e.g. inadequate training, lack of collaborative culture);

- $\quad$ and school factors (e.g. technical and space problems, quality of infrastructure) (p. 49).

Jimoyiannis and Gravani’s second study (2011) on the same SCS program found that the learning process begins with educators identifying learners' ICT related goals, experiences, and preferences; and negotiating course content with the learners. In most schools there was "an atmosphere of mutual trust, support, openness, and cooperation" (p. 224). The importance of a comfortable learning environment for adult digital literacy learners is also supported by Lin (2012). Study participants comprised of middle-aged and elderly women in Taiwan described their difficulty in learning how to use a computer in their home environment: their access to the family computer was restricted and family members were described as impatient and critical. However, when enrolled in an ICT skills program, the women cited the social support of the 


\section{TUTOR-FACILITATED ADULT DIGITAL LITERACY LEARNING}

group as an important factor in their continuing attendance, additional evidence that an encouraging environment of one's peers is beneficial to digital literacy learning (Lin 2012).

The classroom-based model (learners work on the same activities together, guided by an instructor) and the self-paced model (learners select and work on activities independently) are both used in digital literacy learning. However, Xie (2009) learned that the classroom based model presented some disadvantages in comparison to a self-paced model. More experienced adult learners expressed frustration with being delayed by new computer users and new users were also frustrated and embarrassed by being behind their classmates (p. 161). In contrast, classes where the more and less experienced users were balanced "more experienced users voluntarily started helping new users to learn during the session, and the attrition rate tended to be lower in those classes" (p. 161). Wood, Lanuza, Baciu, MacKenzie, and Nosko (2010) found senior citizen computer novices in a computer course expressed an overall preference for scaffolded support whereby "the instructor gradually guides the learner to higher levels of performance through a series of exchanges where learners are encouraged to problem solve, use trial and error, and connect new information to prior knowledge" (p. 853). This study also supports the vital role of the tutor who is able to provide 'just-in-time' instruction. Tutors identified the need for support without having been asked by the learner who "may not have had the knowledge or skills to realize that they need support" (p. 851).

\section{The Learner Web and the Learning Model Research Project}

Developed by Portland State University (PSU), the Learner Web is a web-based learning support platform designed for adult learners who want to accomplish specific learning objectives. The Learner Web offers learning plans relevant to adult learners in a variety of subject areas such as GED preparation, and English language learning. Learners can self-select 


\section{TUTOR-FACILITATED ADULT DIGITAL LITERACY LEARNING}

the learning plans they wish to complete based on their background knowledge, skill level, and interests. The plans in each subject area are comprised of steps designed to help learners achieve a specific goal. Each step includes online and community based resources, and assessment tools such as quizzes. The Learner Web content can be customized; for example, learners can be linked to relevant local education programs and community-based organizations.

In October 2010, as part of BTOP, PSU was awarded a \$3.3 million, 30-month grant by the NTIA to expand the Learner Web as a digital literacy acquisition tool. Working with libraries and other community-based organizations in the BTOP partner regions, PSU and the Learner Web have provided digital literacy training to underserved and vulnerable adult populations. The learning model supported by the BTOP/Learner Web project is a blended approach of self-paced online learning with the in-person support of a tutor. The implementation of the project included the development of three learning plans covering content on digital literacy, broadband consumer education, and career pathways. The three learning plans are offered in both English and Spanish; a toggle feature allows the learner to switch between languages at will. Program implementation also involved the regional work of setting up computer labs, customizing content, recruiting and training tutors, and recruiting adult learners.

The research presented in this paper is a small portion of the larger, ongoing IMLS funded research project "Tutor-Facilitated Digital Literacy Acquisition in Hard-to-Serve Populations: A Research Project” (LG-06-11-0340-11) led by Principal Investigator Dr. Stephen Reder at PSU. The research project will employ a mixed-methods approach to examine the digital literacy acquisition process during the three year BTOP/Learner Web project across six regions. The purpose of this research is to provide useful information about learning and teaching strategies effective in improving digital literacy among vulnerable adult populations, 
TUTOR-FACILITATED ADULT DIGITAL LITERACY LEARNING

and identify insights about the learning processes of individuals who come to public access computer labs for tutor-facilitated support to acquire digital literacy skills.

\section{Methodology}

For this case study, the researchers utilized the data collected in the first phase of fieldwork in one BTOP/Learner Web region. Semi-structured interviews were conducted with two primary groups associated with a BTOP/Learner Web site: the stakeholders (individuals who were essential to the implementation of the BTOP project, such as lab coordinators and program managers) and volunteer tutors working at three different computer labs. The BTOP/Learner Web regional partner identified tutors available for interviews. The interview protocols were developed by the IMLS research project team to elicit narratives from the participants and were piloted prior to use (Appendix A and B). Two researchers conducted field observations by attending an hour of a computer lab session in three different locations (see observation protocol in Appendix C). The computer labs were located in an urban area public library, an urban area workforce center, and a rural area adult learning center. Two researchers separately coded all interview transcripts and lab observations to identify data related to program implementation, the volunteer tutor experience, the learner experience, the learner/tutor relationship, and the learning process; researchers then discussed insights and emerging themes.

\section{Findings and Discussion}

The findings and discussion presented here are organized into three sections regarding this digital literacy learning model for underserved adult populations: program implementation, including volunteer tutor recruitment and engagement; insights on learners; and the learning process.

\section{Program Implementation}




\section{TUTOR-FACILITATED ADULT DIGITAL LITERACY LEARNING}

In the three BTOP/Learner Web sites, two different program implementations were observed. The program at the urban public library and workforce center labs was managed by the same adult literacy organization. The rural adult learning center was implemented independently by the executive director of the center, but with ties to county and community adult literacy and adult education networks. Both implementations drew upon volunteer tutors from within their community.

The cornerstone of program success in the public library and workforce center labs appeared to be the Volunteer Coordinator, employed by the adult literacy organization. The Coordinator managed tutor recruitment and training, as well as learner recruitment. One stakeholder reported almost $100 \%$ volunteer tutor retention in the program labs, which she credited to the Coordinator.

In the recruitment stage, the Coordinator found it effective to have new tutors commit to a specific lab time and location prior to their training. Tutors were also asked to make a sixmonth minimum commitment. This strategy removed the risk of investing training time in tutors who might find that their schedule incompatible; it also appeared to benefit the program because it led to more consistent and sustainable learner/tutor relationships. No other requirements for volunteers were specified. However, the tutors interviewed had backgrounds that might have influenced their commitment to volunteering in this program; for example, one tutor had previously volunteered with the city library and another had previously volunteered with a local technology training initiative. A large part of tutor training was hands-on practice in a Learner Web training site; this site mirrors the plan steps and content available to the learners. Tutors found the Learner Web training site very helpful because it gave them direct experience with the platform from the learners' point of view. In the case of the two urban labs, the Coordinator went 


\section{TUTOR-FACILITATED ADULT DIGITAL LITERACY LEARNING}

with each new tutor to his or her first computer lab session; tutors expressed appreciation for this additional support.

Beyond recruitment and training efforts, the stakeholders and tutors were asked about tutor retention in the BTOP/Learner Web program. Tutor recognition and relationship maintenance were shown to go a long way in terms of retention. Effective strategies included having timely, clear communication and offering support. The Coordinator kept in close contact with the tutors throughout their time with the program, addressing any issues that arose in the labs, and organizing substitutions for ill or out-of-town tutors. Saying "thank you" often was also cited as important for volunteer retention; for example, the Coordinator regularly gave tutors public recognition, such as a small gift when the tutor had volunteered for six months.

In interviews, tutors frequently stated that the positive feedback they received from learners was very rewarding and helped to sustain their engagement in the program. Tutors enjoyed observing learner progress in the program, which is often very tangible, and sharing in learner successes:

I helped her fill out the application on line and I was pretty much guiding her because she was doing it all herself ... she got the job, I was so happy about that, you know, that program actually helped her to fill out the application...-Tutor

Tutors also appreciated the opportunity to develop their own skills working with diverse adult populations. One tutor expressed a desire to become a teacher based on the experience and skills she developed while tutoring.

While the Volunteer Coordinator's primary role was to work with the tutors, she also recruited learners to the program and took steps to sustain their engagement. The Coordinator attended work fairs and other community events to recruit new learners. The program also maintained a "hotline" phone number that was publicized on flyers and elsewhere. All calls were 


\section{TUTOR-FACILITATED ADULT DIGITAL LITERACY LEARNING}

routed directly to the Coordinator who discussed the program with interested new learners and directed them to the computer lab most convenient for their location and schedule. Depending on the lab, the Coordinator also scheduled the learner's first visit. Scheduling staggered intake appointments in busy labs gave the new learner dedicated time with a tutor and the remaining tutors were free to assist others. The Coordinator also queried the Learner Web system to identify learners who had been absent from the program for an extended period of time. She sent reminder letters or made phone calls to encourage their return to the program.

Lab organization was an aspect of program implementation that appeared to impact the learning process, particularly in terms of learner interaction with tutors and other learners. The three labs visited by the researchers all had very different physical arrangements and atmospheres. The public library computer lab was a small room with ten computers arranged in two rows. The lab was full and busy during the evening session that the researchers attended; the two tutors were engaged with learners for the entire hour, frequently moving back and forth to offer assistance. Learners occasionally interacted with other learners, sometimes asking each other questions or showing something they found interesting online. The workforce center lab was a large room with eighteen computers separated by study carrels. Learners were observed rarely interacting with each other. The rural adult learning center lab was housed in a one room portable trailer, which also served as the executive director's office. The lab had a cozy, friendly atmosphere; tutors and learners had friendly interactions with each other. Photographs of successful learners and tutors lined the back wall of the lab, public recognition of their accomplishments. Overall, it appeared that the physical layout of the lab could impact learner interaction with other learners and tutors in terms of their proximity and accessibility to other learners and tutors. 


\section{TUTOR-FACILITATED ADULT DIGITAL LITERACY LEARNING}

Finally, inoperable computers and restricted Internet access were described as detrimental to program implementation. Tutors discussed difficulties with a lack of computer hardware, software, and network support. The workforce center lab tutors had long-standing frustrations with the center's restricted network access which blocked Facebook, YouTube, and other sites. This restriction limited learners' ability to explore the resources and tutorials linked in the Learner Web and progress on their related goals while in the lab.

\section{Insights on Learners}

Findings from the case study analysis of key stakeholder and tutor interviews revealed three themes regarding the learners in the digital literacy learning process: learner motivations, the learners' comfort in the lab environment, and the learner/tutor relationship.

Learner motivation was found to be an important aspect of the digital literacy learning. Their motivation for joining the program affected where in the Learner Web plan steps they began and the approach the tutor might take when introducing the content. Looking for work and learning job-related skills were the most prominent motivations. Job seekers without digital literacy have immediate barriers as the vast majority of job application work is now done online or on computers, including writing a resume and cover letter, emailing potential employers, and submitting online applications and forms. Job seekers were described as being anxious to start by learning about Microsoft Word and Excel right away, though they lacked the foundational skills necessary to do so.

So, a lot of times I have someone come in panicky because they went to a job interview and they were asked about Excel and they don't-you know. So they need computer skills for the job now and especially if it's someone in their 40s or 50s who didn't get computers at school, then that's a special kind of learner because it's someone who wants advanced skills but needs basic skills... -Tutor 


\section{TUTOR-FACILITATED ADULT DIGITAL LITERACY LEARNING}

Some learners wished to use their skills to access education or school-related websites for their children; others were motivated by communicating with distant family and friends. Tutors also identified lifelong learners in the program who were less focused on specific skills; instead their goal was to learn and explore computers and the Internet.

Learner comfort in the lab was influenced by their relationships with tutors and the lab being a safe place to learn. In regards to the learner/tutor relationship, the researchers' analysis suggests that tutors help learners feel comfortable by addressing their fears regarding digital literacy, encouraging learners as they work to achieve their goals, and by building trusting relationships. During the intake process the tutor is essential as they help the learner create an account as well as to navigate the process of signing up for learning plans that meet their individual needs, skills, interests, and goals. Learners often return to the same tutor once they have worked with them during the intake process, developing a trusting and comfortable relationship. Learners may also become more engaged in the content as a result of tutor suggestions of areas of interest to explore or skills they may want to develop and practice. The learner/tutor relationship is possibly a factor in learner attendance, raising the importance of regular tutor commitment to build and sustain relationships with learners. One tutor stated that with some learners 'it's fairly obvious that they need a lot of help and they're going to keep coming back because they want that one-on-one interaction, they want a tutor there to be able to help them when they have questions."

Tutors suggested that learners can be self-conscious about their lack of computer skills and learning at home could be frustrating for them. Although some learners have access to a computer and the Internet at home, they feel more comfortable coming in to the lab to work on their learning plans. This finding echoes the study by Lin (2012) with learners who expressed 


\section{TUTOR-FACILITATED ADULT DIGITAL LITERACY LEARNING}

their discomfort to tutors about competing with other family members for use of the computer and finding it difficult to learn computer skills with a spouse or child directing them.

\section{The Learning Process}

The Learner Web platform is a key aspect of the digital literacy learning process observed in this study, and the self-paced model seems particularly to benefit from a tool like the Learner Web. Each learner's progress is tracked, so the learner is able to enter the platform where they had left off. The executive director of the rural area adult learning center expressed her appreciation of the Learner Web platform, contrasting it with her previous attempts to provide computer skills classes on her own:

I had tried for a couple of years to do computer tutoring on my own...I have the heart and the mind for it, but I am not organized enough. I was not organized enough to see whether I was sequencing [lessons] correctly for people and...I couldn't remember who had done what, who had been absent on any given day.

As a web-based platform, Learner Web is available to learners outside of the program computer labs if they wish to work through the plans alone. System progress indicators are helpful for learners, keeping learners updated on what they have completed and what remains unfinished. Learner Web plan content is structured and sequenced, but it is also flexible, allowing the learner to go back and review or practice earlier lessons and resources. Tutors frequently mentioned that learners return to previous sections for practice; typing and mouse-related games were especially popular among learners.

Learner Web content such as games, videos, and customized local information were valuable and engaging to learners. Local content and resource links helped to make using computers and the Internet much more relevant to the learners. Tutors appreciated the instructional content of the videos and games available to learners. The density of text in Learner Web could be a barrier for beginning learners; one tutor suggested that as part of the digital 


\section{TUTOR-FACILITATED ADULT DIGITAL LITERACY LEARNING}

literacy learning process for low skilled learners "reading should be reinforcement and not introduction." A second concern regarding Learner Web was that content of the learning plans is not clearly explained, requiring tutors to explain content and activities with new learners so they could select appropriate plans for their interests and skills.

Tutors develop their own strategies of how to assist learners and quickly adapt to learners' needs from the first interaction. As learner self-assessment of skill and experience can be misleading, tutors often watch for cues when a new learner first begins. Learners' use of the mouse seemed to be a quick and common indicator of where the learner would need to begin in Learner Web, at least among those with the lowest skills. This watchfulness is continued throughout the tutors' time with a learner; tutors regularly monitor learner activity and offer help either when a learner asks for it or when the tutor thinks they might be need help. This activity reflects the 'just-in-time' approach described by Wood et al (2010).

More than previous teaching experience, tutors indicated that being patient and encouraging with learners were the most important characteristics for successful tutoring. They discussed the ability to identify with learner perspective as beneficial. A tutor at the rural lab was a former learner, and her fellow tutor attributed her success as a tutor to her ability to explain concepts in relatable ways for new learners. Another tutor used a strategy of modeling behavior, conscientiously revealing herself as a fellow learner. For example, when faced with a computer related problem, she modeled troubleshooting in front of learners:

Like today when ...I had so much trouble figuring out - where is that [browser] plug-in? In the past I would have put an out of order sign on that computer and just dealt with it later... But now I think it's useful for the tutorees to see me banging around.

Adjustments in strategy sometimes had to be made in busy labs. One tutor who volunteered at the busy public library lab began directing learners to the video tutorials in 


\section{TUTOR-FACILITATED ADULT DIGITAL LITERACY LEARNING}

Learner Web first and then following up with learners individually. Tutors often encouraged learners to keep a notebook on what they learned and to record their usernames and passwords. Learner notebooks helped alleviate some of the demand on tutors' time reviewing content or tracking usernames and passwords for the learner. In the large workforce center lab, three tutors were observed informally dividing their assistance to learners. One tutor spent a significant part of the hour working with a new learner or waiting for learners to call for assistance; another tutor spent time with a number of learners, sitting or crouching next to them; the third tutor watched learners from the middle of the room, scanning for any who might need help.

\section{Discussion and Conclusion}

This case study examined aspects of self-paced and tutor-facilitated digital literacy learning among underserved populations based on interviews and lab observations in one BTOP/Learner Web region. The findings of this case study suggest key elements of a successful digital literacy learning program useful for public libraries.

When implementing a volunteer supported program, a dedicated and energetic coordinator could greatly influence program success, particularly volunteer retention. Volunteer tutors in this case study were viewed as an investment, and their contributions were frequently acknowledged. Digital literacy tutoring does not require a specialized background, but a patient and encouraging demeanor is important. Recruiting tutors from within the program might be a promising practice because these individuals are uniquely capable of conveying ICT-related concepts in a way that new learners understand.

Digital literacy learners appear to benefit from having a comfortable and supportive place to learn. Even those who have a computer at home attend public computer labs as an unthreatening place to learn. A setting where others are experiencing the same challenges seems 


\section{TUTOR-FACILITATED ADULT DIGITAL LITERACY LEARNING}

to be reassuring for learners and helps to form an encouraging community atmosphere. The community atmosphere of the lab might also be shaped by the physical arrangement of the computers, facilitating or limiting interaction between learners.

The learner/tutor relationship is an important factor for learner engagement and perseverance. This relationship begins from the learner's first visit to a computer lab and may extend over the course of many weeks. As the tutor assists the learner and understands the learner's goals and skills, the tutor can adapt her tutoring strategies to the individual. Tutors who are familiar with a learner can more easily identify when the learner is struggling and help them get "unstuck" whether the problem is technical or conceptual. Tutors provide support and encouragement when a learner is frustrated and express pride in learner's accomplishments.

The self-paced model enables learners to focus on their individual goals and tailor plan steps to their existing skills. Job-seekers may work on more specific skills or work at a different pace than lifelong learners who are simply looking to explore. The structure and sequencing of Learner Web content supports the self-paced learning model and removes the demand on program tutors to develop content and track learner progress. Customizing links to local resources within Learner Web is highly recommended as it increases the relevance of plan content for learners.

The findings in this case study constitute a small portion of the larger IMLS research project. Two primary limitations of this study are the selection of tutors for interviews and the absence of learner interviews. The BTOP/Learner Web region stakeholders identified tutors available for in-person interviews, allowing for selection bias. While the methodology elicited findings on the learner experience, these findings are solely from lab observations and the perspectives of key stakeholders and tutors. As part of the larger IMLS research project at PSU, 


\section{TUTOR-FACILITATED ADULT DIGITAL LITERACY LEARNING}

fieldwork data has been collected from all six regions; a second round of fieldwork will focus on learners in three of those regions. The extensive data and analysis of the IMLS research project could alter the preliminary findings discussed in this case study. The perspective of underserved, low-skilled learners in this program will certainly be a vital addition to the literature on the topic of adult digital literacy learning. A research applications committee composed of representatives from public libraries, adult education, and community-based organizations will advise the research team on the dissemination of project findings.

It is tempting to see the digital divide as a problem that will naturally resolve over time; certainly our use of ICTs in contemporary society appears to always be growing. However, the social inequalities experienced by vulnerable and underserved populations in the United States have remained, or worsened, since the economic downturn of 2008. As more and more essential functions of work, government, and social engagement are available only via a computer and Internet connection, those without affordable access and requisite skill to use ICTs experience yet another hurdle. Library digital literacy programs are a vital resource to not only the individuals they serve - these programs also serve to build workforce, civic, and social capacity in local communities. This case study and the forthcoming research on the self-paced and tutorfacilitated learning model will hopefully contribute to the efforts of libraries looking to build effective and sustainable digital literacy programs. 


\section{TUTOR-FACILITATED ADULT DIGITAL LITERACY LEARNING}

\section{References}

American Library Association (2011). Public library funding and technology access study, 2010-2011[Executive Summary]. Retrieved from:

http://www.ala.org/research/sites/ala.org.research/files/content/initiatives/plftas/2011_20 12/plftas12_execsummary.pdf

American Library Association Digital Literacy Task Force (2013). Digital literacy, libraries, and public policy: Report of the American Library Association Digital Literacy Task Force. Retrieved from: http://www.districtdispatch.org/wpcontent/uploads/2013/01/2012_OITP_digilitreport_1_22_13.pdf

Becker, S., Crandall, M. D., \& Fisher, K. E. (2010). Opportunity for all: How the American public benefits from Internet access at U. S. libraries (IMLS-2010-RES-01). Washington, D.C.: Institute of Museum and Library Services.

Duff, A. S. (2011). The Rawls-Tawney theorem and the digital divide in postindustrial society. Communications, 62(3), 604-612.

Eubanks, V. (2011). Digital dead end: Fighting for social justice in the information age. Cambridge: MIT Press.

Hargittai, E. (2002). Second-level digital divide: Differences in people's online skills. First Monday, 7(4). Retrieved from: http://www.firstmonday.org/htbin/cgiwrap/bin/ojs/index.php/fm/article/view/942/864

Horrigan, J. B. (2010). Broadband use and adoption in America (Omnibus Broadband Initiative working paper series no. 1). Retrieved from: http://hraunfoss.fcc.gov/edocs_public/attachmatch/DOC-296442A1.pdf 


\section{TUTOR-FACILITATED ADULT DIGITAL LITERACY LEARNING}

Jaeger, P. T., Bertot, J. C., Thompson, K. M., Katz, S. M., \& DeCoster, E. J. (2012). The intersection of public policy and public access: Digital divides, digital Literacy, digital inclusion, and public libraries. Public Library Quarterly, 31(1), 1-20. doi:10.1080/01616846.2012.654728

Jimoyiannis, A., \& Gravani, M. (2011). Exploring adult digital literacy using learners' and educators' perceptions and experiences: The case of the Second Chance Schools in Greece. Educational Technology and Society, 14(1), 217-227.

Jimoyiannis, A., \& Gravani, M. (2010). Digital literacy in a lifelong learning programme for adults: Educators' experiences and perceptions on teaching practices. International Journal of Digital Literacy and Digital Competence, 1(1), 40-60.

Lin, C., Tang, W., \& Kuo, F.Y. (2012). "Mommy wants to learn the computer": How middleaged and elderly women in Taiwan learn ICT through social support. Adult Education Quarterly, 62(1), 73-90.

Mossberger, K., Tolbert, C. J., \& Stansbury, M. (2003). Virtual inequality: Beyond the digital divide. Washington, D. C.: Georgetown University Press.

National Telecommunications and Information Administration (NTIA). (1995). Falling through the net: A survey of the "have nots" in rural and urban America. Retrieved from http://www.ntia.doc.gov/ntiahome/fallingthru.html

National Telecommunications and Information Administration (NTIA). (2011). Digital nation: Expanding Internet usage. Retrieved from: http://www.ntia.doc.gov/legacy/reports/2011/NTIA_Internet_Use_Report_February_201 1.pdf 


\section{TUTOR-FACILITATED ADULT DIGITAL LITERACY LEARNING}

Taylor, N. G., Jaeger, P. T., McDermott, A. J., Kodama, C. M., \& Bertot, J. C. (2012). Public libraries in the new economy: Twenty-first century skills, the Internet, and community needs. Public Library Quarterly, 31(3), 191-219. doi:10.1080/01616846.2012.707106

Van Dijk, J. A. (2005). The deepening divide: Inequality in the information society. Thousand Oaks, CA: Sage Publications.

Wood, E., Lanuza, C., Baciu, I., MacKenzie, M., \& Nosko, A. (2010). Instructional styles, attitudes and experiences of seniors in computer workshops. Educational Gerontology, 36(10-11), 834-857. doi:10.1080/03601271003723552

Xie, B. \& Bugg, J.M. (2009). Public library computer training for older adults to access highquality Internet health information. Library \& information science research, 31(3), p. 155-162. doi:10.1016/j.lisr.2009.03.004 


\section{TUTOR-FACILITATED ADULT DIGITAL LITERACY LEARNING}

\section{Appendix A}

\section{Interview Protocol: Stakeholders}

\section{Welcome}

Thanks for coming to this interview session. You're here today to participate in an interview for a study of engagement in online learning environments focused on teaching digital literacy skills. The purpose of this interview is for me to learn your experience of facilitating the BTOP digital literacy learning plans. I may want to contact you again if I have any follow-up questions from this interview. I'll ask your permission to do so when this interview is complete. Your name will remain anonymous and any remarks that you make during the interview will remain confidential. The interview will take approximately one hour.

\section{Introduction}

- Tell me about how you got started with the BTOP project.

- What draws you in to this kind of work? What motivates you to participate?

- Are the resources you are investing (e.g., time, money) in the program worth the rewards?

- What has been your experience, if any, with digital literacy programs like this? How does this one compare?

\section{Sustaining BTOP}

- Why is it important for learners to gain proficiency in digital literacy?

- Why do you think adults come to this program?

- What factors do you think encourage adults to stay in BTOP?

- What factors encourage adults to leave BTOP?

- What do you expect from the tutors? 
- What do you expect from the learners?

- What aspects of the BTOP program do you consider most important to recruiting and retaining learners and tutors?

- What do you wish you knew more about adult learners?

- How would you define success for this program?

- What are some of the important lessons you have learned in your time with this program?

\section{Suitability of Content}

- Does the BTOP program adequately meet the personal and professional goals of the Learners?

- Are Learners able to acquire the skills supported by the BTOP curriculum?

- How can learners further develop their skills beyond the BTOP curriculum?

- What are your thoughts about the way BTOP personalizes the curriculum for individual learners? Explain.

- Is the BTOP on-line platform well organized and easy for learners to navigate? Explain.

\section{Technology}

- Have you encountered any technical issues when going through the BTOP learning plans? If yes, explain.

- How functional and/or usable is the technological learning environment to a wide range of learners?

- Explain the learning environment in a computer lab.

\section{Program Evaluation}




\section{TUTOR-FACILITATED ADULT DIGITAL LITERACY LEARNING}

- Tell me about your own evaluation of the BTOP program. How does learner involvement in the BTOP program enhanced learners' personal and/or professional engagement? Do you have any observations that help track this?

- Is there anything else you would like to tell me about your experiences with BTOP?

\section{Conclusion}

Thank you for your time on this interview. I want to remind you again that your responses will remain confidential. May I contact you again for follow-up questions and to check if I understand your responses correctly? 


\section{TUTOR-FACILITATED ADULT DIGITAL LITERACY LEARNING}

\section{Appendix B}

\section{Interview Protocol: Tutors}

\section{Welcome}

Thanks for coming to this interview session. You're here today to participate in an interview for a study of tutors engagement in online learning environments focused on teaching digital literacy skills. The purpose of this interview is for me to learn your experience of participating as a tutor in tutors-facilitated e-learning lessons, such as the BTOP digital literacy learning plans. I may want to contact you again if I have any follow-up questions from this interview. I'll ask your permission to do so when this interview is complete. Your name will remain anonymous and any remarks that you make during the interview will remain confidential. The interview will take about one hour.

\section{Tutor-Program Interaction}

- Describe how you came to know about this program.

- How long have you been tutoring?

- Why did you come to this lab? Are there any other labs you go to? (If yes, how are the labs you go to the same/different?)

- Describe a typical tutoring session for you. (How do you get started? How do you move through the tutoring process?)

- As a tutor do you ever become frustrated? If yes, what do you use to work through your struggles? Can you give me an example of a time when you did this?

- Do you have any special tips or tricks you could give to other Tutors to help them be more successful?

\section{Learner Tutor Interaction}




\section{TUTOR-FACILITATED ADULT DIGITAL LITERACY LEARNING}

- Tell me about the different types Learners with whom you work. For example, do they have specific learning characteristics that stand out as unique with regard to the learning plans (e.g. do they often review content from the same plan, do they have more than one plan open and active at a time, do they jump between learning plans, do they choose learning plans according to their goals, do they work linearly through the plans provided to them?)

- What do you do to help the learners you work with learn?

- Does what you do vary from one learner to the next?

- Do different learners need different types of support? Which learners need what kind of support?

- What do you try to find out about a learner to be able to provide the support they need?

- Describe a Learner you have really been able to help. How did you approach working with him/her?

- Describe a Learner who you have found hard to help. How did you approach working with him/her?

\section{Implementation in real-world contexts}

- Are the Learners able to learn and use the skills they are taught through the LW system?

- How are the skills taught through LW affecting Learners' lives? Explain.

- Has the program been supportive of language learning (learners' needs)? Explain.

\section{Learner-Learner Interactions}

- Have you seen Learners talk and/or work together on learning plans? If yes, please describe. 
TUTOR-FACILITATED ADULT DIGITAL LITERACY LEARNING

\section{Tutor Expectations:}

- If you had a friend or family member who was interested in becoming a tutor, what advice would you give him/her in order to make his/her time most successful? Explain.

\section{Tutor Support}

- What training did you receive that helped you become a good tutor?

- Do you talk with other tutors? If yes, what do you talk about?

\section{Tutor Experience}

- Tell me about a time when you felt successful as a tutor. What happened? How did you feel? What did you take away from the experience?

- Tell me about a time when you did not feel very successful as a tutor. What happened? How did it feel? What did you take away from the experience?

\section{Improving the Program and Next Steps:}

- What about the program keeps you coming back?

- Describe a time when you learned something new as a result of your tutoring.

- In what ways, if at all, has this program helped support language learning?

- If you could change one thing about the Learner Web program, what would it be? Why?

- If you could change one thing about the training program in general, what would it be? Why?

- What's next for you?

- Is there anything else you would like to tell me about being a tutor?

\section{Conclusion}




\section{TUTOR-FACILITATED ADULT DIGITAL LITERACY LEARNING}

Thank you for your time on this interview. I want to remind you again that your responses will remain confidential. May I contact you again for follow-up questions and to check if I understand your responses correctly? 
TUTOR-FACILITATED ADULT DIGITAL LITERACY LEARNING

\section{Appendix C}

\section{Lab Observation and Field Notes}

\section{Informing the Participants}

Inform the participants in the lab you are observing about the focus and purpose of your observation. Say that you'll be taking notes, but you will not interrupt to talk to them. Emphasize that you're not observing them but instead the contexts within the lab and the conditions that unfold within the lab (including tutor-learner interactions).

\section{Specifics for Field Notes}

Create a written record of your field activities, observations and summary thoughts.

Record date and location information in a very detailed manner so that others can know exactly when, where, and under what conditions your work was done. We may want to return to return to the same labs to observe changes over time (or to compare labs with one another).

Create a detailed record that includes information such as:

- Lab set-up

- Time of observations (hours of the day, days of week, length of events)

- Lab characteristics

- Number of learners in the lab

- Number of tutors in the lab

- Average length of time individuals spend working

- Learner engagement with online materials

- Learner engagement with peers

- Learner engagement with tutor(s)

- Noise level 
TUTOR-FACILITATED ADULT DIGITAL LITERACY LEARNING

- Activity level in the lab (in general)

- What happens when learners ask for help

- What happens when learners don't ask for help

- How do tutors position themselves

- Frequency of tutor-learner interaction

- Fluency of tutor-learner interaction

- Length of tutor-learner interaction

- Interactive patterns between learners and tutors

- Interactive patterns between learners and other learners

- Nature of support provided (coaching, showing/demonstrating) 